\title{
Research status and application of prefabricated concrete frame joints
}

\author{
Mo Sha ${ }^{1}$, Ping Liu ${ }^{1, *}$, Jierui $\mathrm{Gao}^{1}$, and Hua $\mathrm{Ma}^{2}$ \\ ${ }^{1}$ Tianjin Ren'ai College, Tianjin 301636, China \\ ${ }^{2}$ Key Laboratory of Engineering and Structural Retrofit, Beijing University of Technology, Beijing \\ 100124, China
}

\begin{abstract}
Prefabricated concrete structure has the advantages of less energy consumption, easy quality control, fast construction speed, good construction site environment, and less contraction crack. As one of the important development directions of building structure at home and abroad, it is not only conducive to the development of China's construction industrialization and the improvement of production efficiency, but also greatly reduces the construction waste. The design of the connection between beam and column in the core plays an important role in the normal use and seismic performance improvement of the whole concrete structure. This paper reviews the research progress of prefabricated concrete frame joints both at home and abroad, introduce some applications of new connection, and analyses the merit and demerit of various connection methods and future development trend, in order to provide design reference for the engineering application of prefabricated concrete structure.
\end{abstract}

Keywords: Prefabrication; Concrete; Frame node; Seismic performance; Design method.

\section{Introduction}

With the continuous development and progress of industrial technology, the construction industry is also due to the improvement of factory production technology, the emergence of new buildings, namely prefabricated buildings. Prefabricated building is developing rapidly all over the world because of its mass production of components, high quality, short construction period, environmental protection and low energy consumption. According to relevant data, as early as the 17 th century, Europe began to move towards the construction industrialization. After the end of World War II, the economy of various countries was depressed and the population and labor force were extremely scarce. In order to stimulate economic development and solve the housing problem of residents, Western European countries vigorously promoted the process of construction industrialization. Additionally, the fifth frame project of 2003G6RD-CT-2002-00857 initiated by the European Union has greatly promoted a more comprehensive understanding of the seismic performance of prefabricated buildings in Europe, and further promoted the development and change of seismic joint technology of prefabricated buildings ${ }^{[1]}$. In the early 1970 s,

*Corresponding author: liuping021031@126.com 
prefabricated buildings were introduced into the United States from Europe. The government attached great importance to this technology and issued a series of relatively perfect specifications through the U.S. Department of development. At the same time, the American Prestressed Concrete Institute compiled PCI design manual to ensure the construction quality of prefabricated buildings. Since then, prefabricated buildings have formed a complete system in the United States ${ }^{[1]}$. As one of the most earthquake prone countries in the world, Japan has always been in the forefront of the world in the study of seismic performance of buildings. In the 1990s, prefabricated houses in Japan already accounted for about $30 \%$ of the whole construction industry, and the buildings in Japan are generally light frame structure or wood structure, so as to avoid the damage after the earthquake ${ }^{[2]}$.In the $1990 \mathrm{~s}$, Singapore began to adopt the forced assembly strategy, which increased the overall prefabricated building share to more than $70 \%$, and solved the people's housing demand through the strategy of assembly industrialization ${ }^{[2]}$. China's building industrialization started at the same time as new China's construction industrialization, but the low technical level caused the lack of seismic performance of the early prefabricated building structure. In particular, the severe damage of prefabricated buildings in 1976 Tangshan earthquake made people doubt or even deny the seismic performance of prefabricated buildings. However, since the 1970s, in many earthquakes abroad, most precast concrete structures have experienced the test of different intensity earthquakes, showing good seismic performance ${ }^{[3]}$, This shows that the prefabricated concrete structure with reasonable design and standard construction can have seismic capacity. In recent years, with the emergence of labor shortage in the construction industry, the requirements of green construction, the trend of housing industrialization is increasingly obvious. In 2016, the CPC Central Committee and the State Council issued several opinions on Further Strengthening the management of urban planning and construction, which pointed out definitely that we should vigorously promote prefabricated buildings, increase policy support, and strive to use about 10 years to make prefabricated buildings account for $30 \%$ of new buildings ${ }^{[4]}$.Under the great attention of the Party Central Committee and the State Council, China's prefabricated building has achieved phased development, various technical standards have been gradually improved, and the construction capacity of enterprises has been continuously improved.

In the prefabricated concrete frame structure, the beam-column joint is the core part of the whole structure seismic performance. Its safety and reliability is very important for the normal use and seismic performance of the whole building. This paper summarizes the research status of joint connection technology of prefabricated concrete frame structure at home and abroad, and compares the technical regulations at home and abroad. It is expected to provide a reference for the development of prefabricated concrete frame structure and the seismic design of the structure.

\section{Research status of prefabricated concrete frame joints}

In the early 1970s, prefabricated buildings were introduced into the United States from Europe. The government attached great importance to the technology and issued a series of relatively perfect specifications through the U.S. Department of development. At the same time, the American precast stress Concrete Association (PCI) compiled "PCI design manual" to ensure the construction quality of prefabricated buildings. Since then, prefabricated construction has formed a complete system in the United States, and made a rapid breakthrough in the construction industry. With the continuous use of prefabricated buildings, the seismic problem of prefabricated buildings has been paid more and more attention. From 1991 to 2003, the PRESS project, which was jointly carried out by NSF, PCI and RCMAC, systematically studied the connection structure of precast stress precast 
concrete structures. Hossein parastesh et al. Proposed a new ductile bending beam column connection, which reduces the use of concrete, delays the development of diagonal cracks, and helps to avoid the bad failure mode in the connection under strong earthquake ${ }^{[5]}$ (as shown in Fig. 1).

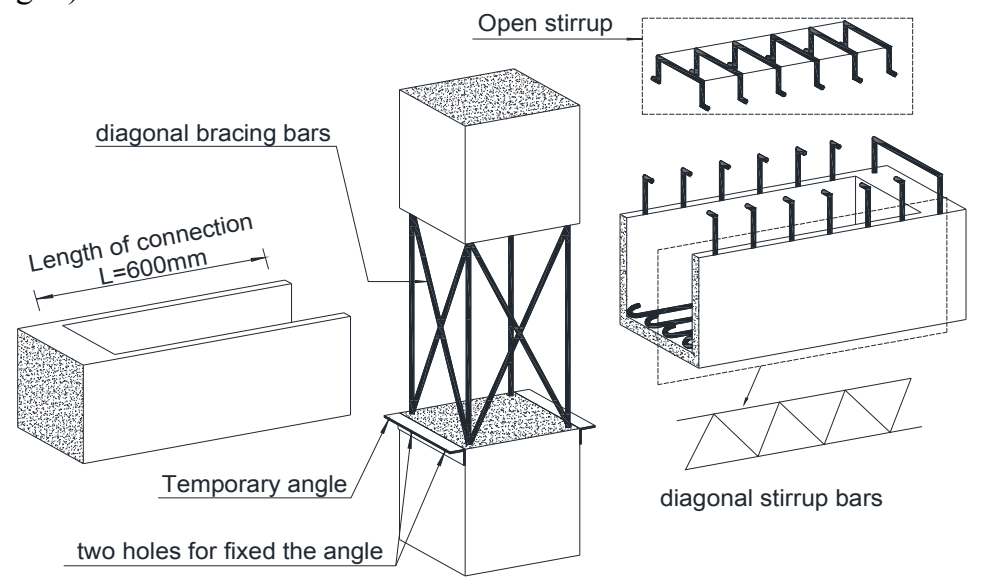

Fig. 1. Structural diagram of ductile beam column joints proposed by parastesh et al.

In the course of building industrialization in Europe, the relevant technical standards of prefabricated buildings have been constantly improved, and the problems of building quality and earthquake resistance have also been widely valued by governments. Due to the long-term lack of in-depth understanding and systematic understanding of the seismic performance of prefabricated buildings, the European Union launched the fifth frame project (G6RD-CT-2002-00857) in 2003. This project has more than ten units from different countries, such as Milan Polytechnic University, Athens National University, Proet precast concrete company, EU joint research center, etc. in the project, each unit cooperates with each other to study the seismic performance of new prefabricated buildings and provide experimental and theoretical basis for the revision of Eurocode 8. The successful development of this project greatly promotes a more comprehensive understanding of the seismic performance of prefabricated buildings in Europe, and further promotes the development and change of seismic joint technology of prefabricated buildings. In addition, yuksel et al. Studied the dry industrial joint and the wet residential joint, and proved that both of them have good seismic performance ${ }^{[6]}$ (as shown in Fig. 2. and Fig. 3.).

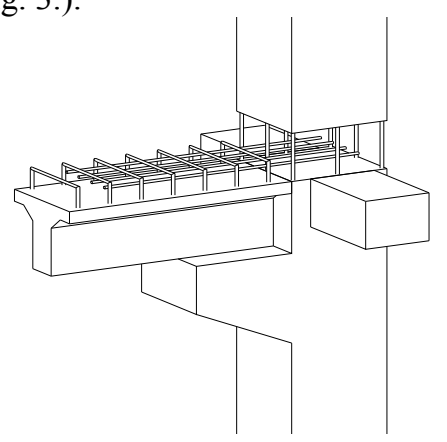

Fig. 2. Industrial connection node.

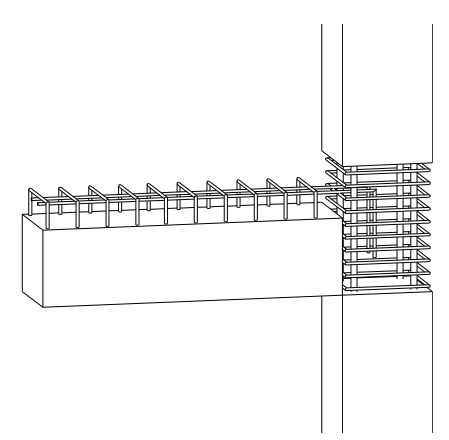

Fig. 3. Residential connection node.

In China, the research on the seismic resistance of prefabricated building joints started relatively late, and the application of precast concrete began in the 1950s. At that time, the overall performance of prefabricated concrete structure was poor, and the problems of 
seismic resistance, thermal insulation and component industrialization were prominent, especially the key technology of joint connection had not been broken through, which led to the gradual adoption of precast concrete by traditional building structures since the 1990s Generation $^{[3]}$. In recent decades, due to the fast progress of China's industrialization process and the strong support of national policies, China's prefabricated buildings once again sprang back to life, and a series of innovative achievements have been made in the seismic research of joints. Some researchers have done a lot of experimental research and theoretical simulation from the frame combination and frame shear wall structure, and achieved rich results. Yu Zhiwu and Peng Xiaodan ${ }^{[9]}$ of Central South University proposed a new type of U-shaped reinforcement (as shown in Fig. 4) and made relevant experiments. The experimental research shows that this kind of U-shaped reinforcement anchorage technology is reliable and equivalent to ordinary cast-in-place concrete structure in seismic performance.

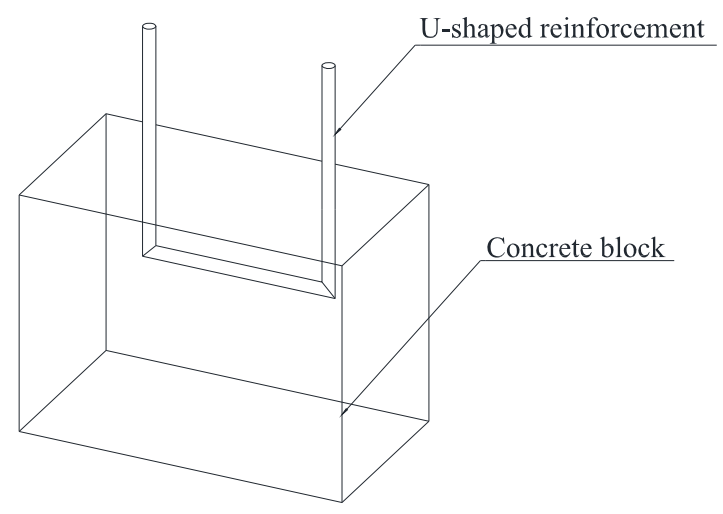

Fig. 4. U-shaped reinforcement anchorage.

Because the prefabricated building frame node seriously restricts the advantages of prefabricated building, domestic scholars hold the concept of "equal to cast-in-place"[7], improve and explore the prefabricated building frame node in different degrees, and a large number of excellent improvement methods and measures emerge. Some researchers ${ }^{[7]}$ put forward the idea of "large diameter, few pieces" of new anchorage and additional reinforcement lap hybrid way to improve the seismic performance of prefabricated building joints, and adopted low cycle repeated tests. The research results show that the seismic performance of prefabricated joints adopting the idea of "large diameter, few pieces" of new anchorage and additional reinforcement lap hybrid way is similar to that of cast-inplace joints. After the test, the test results are reproduced by the finite element model, and the effect of disparate parameters on the seismic performance of the beam end bottom reinforcement anchored precast beam column connection is further analysed through the change analysis of parameters. At the same time, a new connection mode of prefabricated frame beam column with high strength and small diameter is put forward, and relevant research and test are carried out. The results show that this connection mode is better than the cast-in-place joint. This kind of connection greatly simplifies the force transfer mode between the precast beam and column anchored at the bottom of the beam end, and is convenient to establish the static calculation and restoring force model of the precast beam and column connection node anchored at the bottom of the beam end, which lays a foundation for further research and application of this kind of prefabricated concrete frame structure $^{[10]}$. This kind of prefabricated component is convenient for factory production, simple installation and high construction efficiency. The deficiency lies in that this connection form is still in the stage of theoretical research, which is less used in 
engineering practice and has less influence. In the same case, the consumption of reinforcement is large and the quality of reinforcement is high. Some researchers ${ }^{[8]}$ put forward a new type of precast RC frame joint, which uses steel plate welding to connect precast beams and columns by embedded section steel. Through the experimental study and numerical simulation, the hysteretic curve, skeleton curve, energy consumption of the joint, stiffness, bearing capacity and ductility are analysed. The results indicate that the seismic performance of the new precast $\mathrm{RC}$ frame joint is equivalent to that of the traditional castin-place beam column. Compared with the cast-in-place beam column joints, the overall crack development of the new joints is more sufficient, and the stiffness, bearing capacity and degradation of the new joints are better than the cast-in-place joints. Through the finite element analysis, the effect of disparate parameters on the seismic performance of the new type of beam-column joints is obtained. Finally, it is concluded that the $200 \mathrm{~mm}$ steel plate is the most suitable for the new type of prefabricated $\mathrm{RC}$ frame joint. The most remarkable feature of this kind of joint is that the section steel is used to replace the traditional reinforcement to connect the beam and column at the joint, which significantly improves the joint stiffness and bearing capacity, and makes the overall crack development of the component more fully. However, the quality of this type of connection depends too much on the quality of the weld seam in the construction process, and the quality requirements of the weld and steel are too high. In practical engineering, this type of joint consumes a large amount of steel, and the engineering quality is difficult to guarantee, which is not economical. Some researchers ${ }^{[2]}$ put forward a more simple and efficient fabricated beam column joint, namely fully assembled joint. The connection between the beam and the column is completely made of steel plate and bolt. Because this connection needs to open 8 bolt holes respectively between the beam and the column, it is abbreviated as eight bolt joint (as shown in Fig. 5 and Fig. 6). The experimental results point out that the yield strength and bearing capacity of the eight bolt joints are much better than that of the cast-inplace joint, which indicates that the joint has good seismic performance. The finite element software ABAQUS is used for simulation, and the results show that the design of this joint is more successful. After theoretical calculation, it is found that after reducing the number of bolts to six bolts, the joint form also meets the design requirements. This kind of joint connection form is far superior to the traditional cast-in-place joint in anti-seismic ability, greatly improving the overall stability and safety of the prefabricated building; in the field operation, it avoids the defects of wet operation, makes the field operation more convenient, improves the installation speed, and at the same time, it can adjust the number and spacing of bolts according to the actual situation in the actual project, which is more practical Add flexibility and convenience. In addition, Zhu Zhangfeng, Qian Jiaru, Zheng Yongfeng and other scholars have studied the seismic performance of prefabricated building joints, and proposed improvement measures.

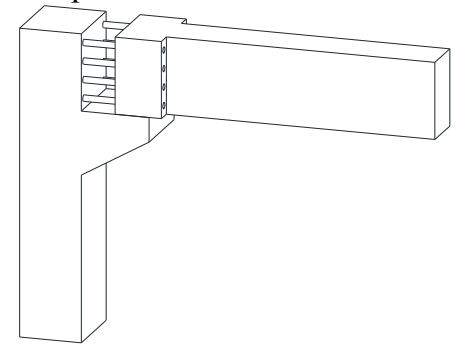

Fig. 5. Before inserting the bolt.

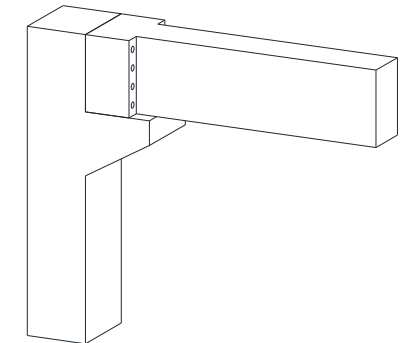

Fig. 6. After inserting the bolt. 


\section{Summary and Prospect}

This paper reviews the research results of precast concrete frame joints at home and abroad. After a long period of research, the research of precast concrete frame joints in Europe and the United States has been relatively mature and has formed a relatively sound theoretical system. Compared with European and American countries, the domestic prefabricated concrete frame joints start late. In the past decade, due to the strong support and encouragement of the state, prefabricated buildings have been developing continuously. The seismic problems of the joints that restricted the prefabricated buildings in the past are gradually being solved. The research of prefabricated frame joints in China has achieved phased results, and many feasible new connection methods have emerged. These joint connection research is more in the laboratory test research and finite element software data simulation, so in the later research process, we should pay more attention to the practical application of the project, to provide sufficient theoretical foundation and reference methods for the improvement and formulation of China's relevant technical standards.

\section{Acknowledgement}

This research was financially supported by Innovative Training Program for College Students in Tianjin (Number 202014038037).

\section{References}

1. Wu Gang, Feng Decheng. Research progress on fundamental performance of precast concrete frame beam-to-column connections [J]. Journal of Building Structures, 39, 2: $1-15,(2018)$

2. Qin qiqi. Research on seismic behavior of a new type of concrete assembled beamcolumn joint [D]. ANHUI JIANZHU UNIVERSITY, (2020)

3. Wang Jun, Zhao jida, Hu zongyu. Review and thinking on development of building industrialization in China [J]. China Civil Engineering Journal, 49, 5: 1-8, (2016)

4. General Office of the State Council. Guidance of General Office of the State Council on vigorously developing prefabricated buildings [J]. Housing industry, 10: 10-12, (2016)

5. PARASTESH H, HAJIRASOULIHA I, RAMEZANI R. A new ductile momentresisting connection for precast concrete frames in seismic regions: an experimental investigation [J]. Engineering Structures, 70, 9: 144-157, (2014)

6. YUKSEL E, KARADOGAN H F, BAL E, et al. Seismic behavior of two exterior beam-column connections made of normal-strength concrete developed for precast construction [J]. Engineering Structures, 99: 157-172, (2015)

7. Guan Dongzhi. Research on seismic behavior of precast beam column joints with bottom bars anchored in beam ends.[D].Nanjing: Southeast University, (2017)

8. Wang Su. Study on seismic behavior of new precast RC frame joints. [D]. Xuzhou: China University of Mining and Technology, (2019)

9. Yu Zhiwu, Peng Xiaodan, Guo Wei, Peng miaopi. Seismic behavior of U-type hoop connections in prefabricated shear walls [J]. Journal of Zhejiang University (Engineering Edition), 49, 05: 975-984, (2015)

10. Wu Chao, Xie Jianhe, Liu Feng. Research progress and prospects on beam-to-column connections of precast concrete frame [J]. Concrete, 4: 128-137, (2020) 